Acta Technologica Agriculturae 4

Nitra, Slovaca Universitas Agriculturae Nitriae, 2019, pp. 128-133

\title{
MATHEMATICAL MODELLING OF SOLAR THERMAL COLLECTORS AND STORAGES
}

\author{
János TÓTH, István FARKAS*
}

Szent István University, Gödöllő, Hungary

\begin{abstract}
Block-oriented modelling is a powerful tool in system design. The models developed this way can be used to study various systems, such as solar thermal systems. In the work presented, main goal is to compare different mathematical models of solar thermal devices. The difference in accuracy of such models in respect to the possibilities of a hardware-in-the-loop simulation will be discussed. Two models of solar thermal collectors will be compared and used in a system containing two different heat storages in order to study the behaviour of these models. The tests were carried out in a Simulink based block-oriented environment called SimSolar.
\end{abstract}

Keywords: block-oriented simulation; comparison; modelling; solar energy

The development of solar systems has been highly speeded up in the recent years. For this purpose, a lot of experiments were made and a lot of prototype systems were built. Nevertheless, it is expensive to build a physical system to perform experiments. With the aid of the computer assisted modelling methods such costs can be reduced, but these algorithms were created for a specific task and they do not provide very much flexibility.

Model-based design is a possible way to resolve this issue (Paterno, 2000). This design method utilizes mathematical models and the simulation of them to reduce the costs and to speed up the test phase. This approach is useful to analyse and develop an existing solution as well (Bilčík et al., 2018). There are working software packages for solar applications that use this method, for example the TRNSYS software (Kyn and Urban, 2013;TRNSYS, 2009) or the Polysun software (Lacoste et al., 2010). Reputation of these programs shows the potential in this field and a need for a reliable solution for educational intent. These commercial program-packages are proven-to-work, but they cannot be used for development purposes due to their prices.

Extension of the model-based design is the hardware-inthe-loop (HIL) simulation, in which real-time data are used for the model; this is achieved by using embedded systems and sensors. The "hardware" part can be either FPGA devices or more common embedded systems, such as Arduino or Raspberry Pi (Velasquez et al., 2017). There are two main approaches to make a HIL simulation - one in which the simulation runs on a host machine and the embedded system acts like an input (a complex simulation can be built without the hardware limitations of the embedded system in such manner). The other method includes the entire simulation running on the embedded system; the system becomes portable, but it requires more advanced hardware in such case (Ilyas et al., 2018).
The presented simulations were performed using a custom-made Simulink library called SimSolar (Tóth and Farkas, 2017) software, which is a block-oriented modelling environment.

In this paper, the mathematical models of solar thermal collectors and the connected heat storages are presented. Aforementioned models are studied in a block-oriented simulation environment to show the differences in accuracy and to study the behaviour of such models in a system.

\section{Material and methods}

Used mathematical models of the solar thermal collectors and heat storages and the metrics of the comparison are presented in this section.

\section{Models of solar collectors}

Collector is a device converting the radiant energy of the Sun into heat in a solar thermal system. This component primarily determines the efficiency of the system, because the gathering of the energy occurs here. The two mathematical models of the collector, which describe the same device, are presented in this section.

\section{Hottel-Vhillier (H-V) model}

The Hottel-Vhillier model (Farkas, 1999) was applied to a collector as shown in Fig. 1.

Using the above introduced notations, the mathematical model is as follows:

$$
T_{c o}(\tau)=T_{w}(\tau)+\frac{I(\tau)}{\kappa_{a w}}\left(T_{c i}(\tau)-T_{w}(\tau)-\frac{I(\tau)}{\kappa_{a w}}\right) \cdot \exp \left(\frac{-\kappa_{m w} \cdot w \cdot I}{c \cdot \frac{d m}{d \tau}}\right)
$$

Contact address: István Farkas, Szent István University, Department of Physics and Process Control, Páter Károly u. 1, Gödöllő, H-2100 Hungary, e-mail: Farkas.Istvan@gek.szie.hu 
where:

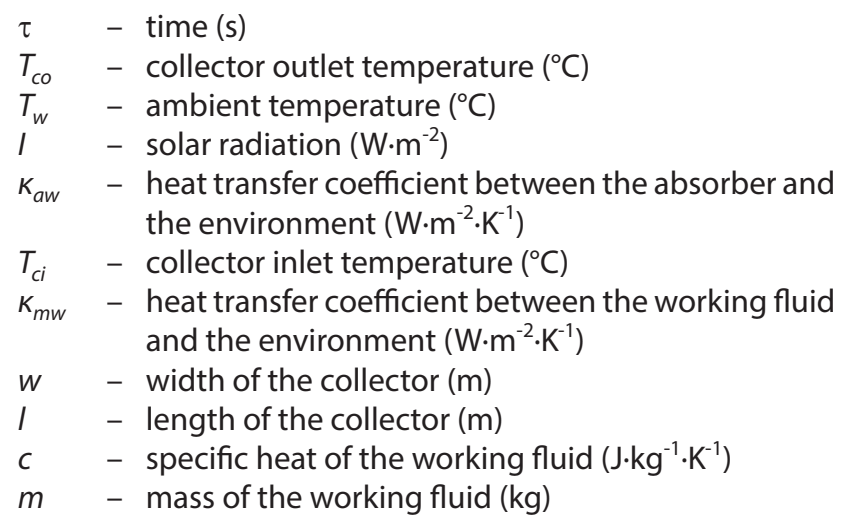

The overall heat transfer parameters $\kappa_{a w}$ and $\kappa_{m w}$ are needed to be identified in order to get proper simulation results.

\section{Differential Equation (DE) model}

The Differential Equation model (Farkas, 1999) of collector (Fig. 2) represents a more complex approach in comparison to the $\mathrm{H}-\mathrm{V}$ model.

The governing equations of the model can be described as:

$$
\begin{gathered}
\rho \cdot c \cdot V \frac{d T_{c o}}{d \tau}=I(\tau) \cdot w \cdot I \cdot \eta_{o p t}-\kappa \cdot w \cdot l \\
\left(T_{\text {avg }}(\tau)-T_{w}(\tau)\right)+\frac{d m}{d \tau} \cdot c\left(T_{c i}(\tau)-T_{c o}(\tau)\right)
\end{gathered}
$$

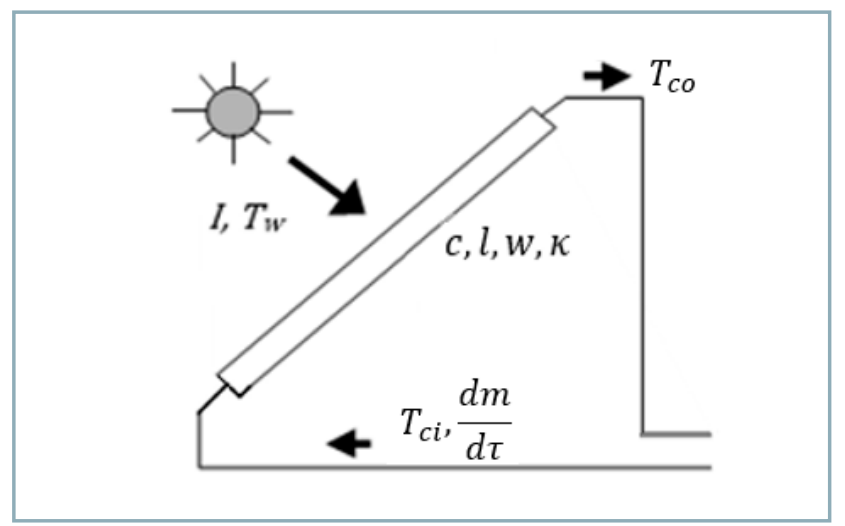

Fig. 1 Scheme of the collector

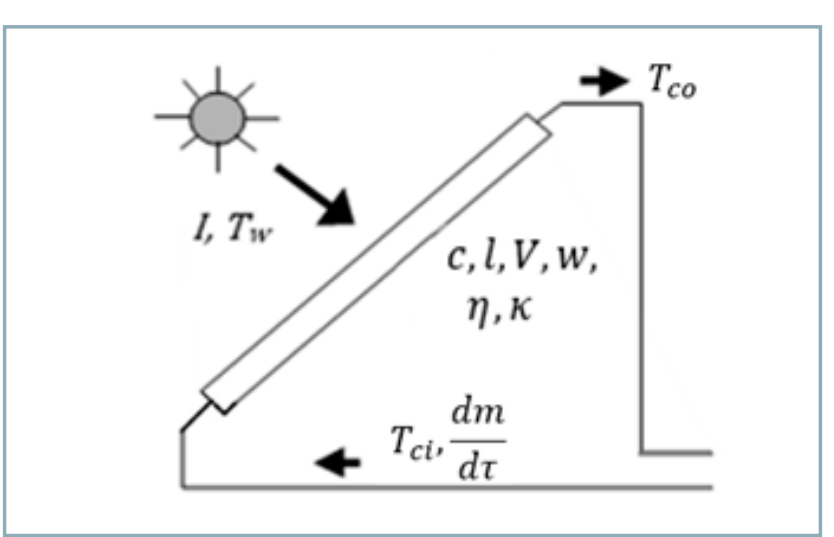

Fig. 2 Scheme of the collector where the average temperature of the collector:

$$
T_{\text {avg }}(\tau)=\frac{T_{c i}(\tau)+T_{c o}(\tau)}{2}
$$

where:

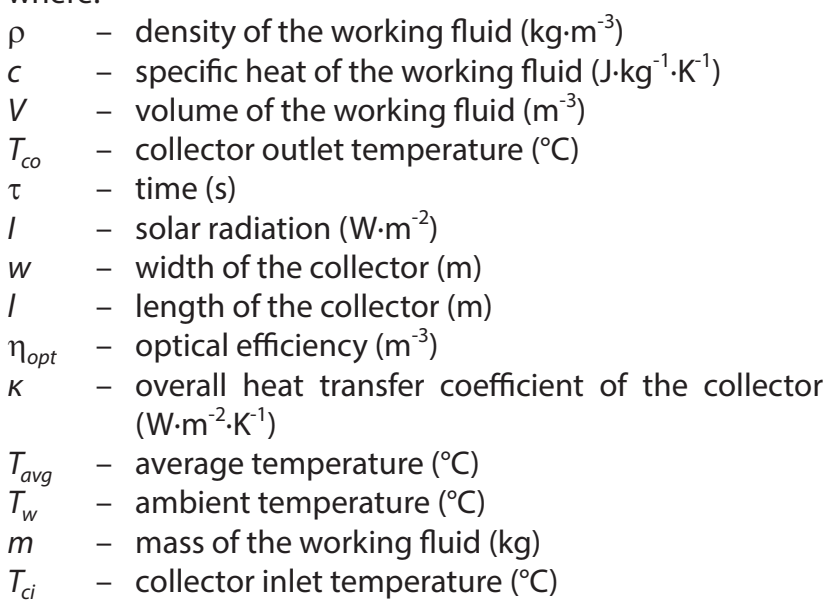

The parameters $\eta_{\text {opt }}$ and $\kappa$ cannot be measured easily, so they are needed to be identified via measurements.

\section{Models of heat storages}

Heat storage plays an important role in a solar thermal system, because the time of the energy collection frequently differs from the time of the consumption of this energy, this thermal energy needs to be stored. The heat storage uses fluid to store the heat energy; this fluid was water in case of the simulations. Two different types of heat storage devices were selected, because these two are the most commonly used in small-scale household solar thermal systems. The two mathematical models of the storage are discussed in this section.

\section{Mixed heat storage}

Considering the mixed heat storage, the outlet of the collector and the inlet of the storage meet in a common space, this is where the transfer of the energy occurs; therefore, the temperatures of the storage outlet and the collector inlet are the same.

This model of the storage can be seen in the literature (Duffie and Beckman, 2013) as shown in Fig. 3.

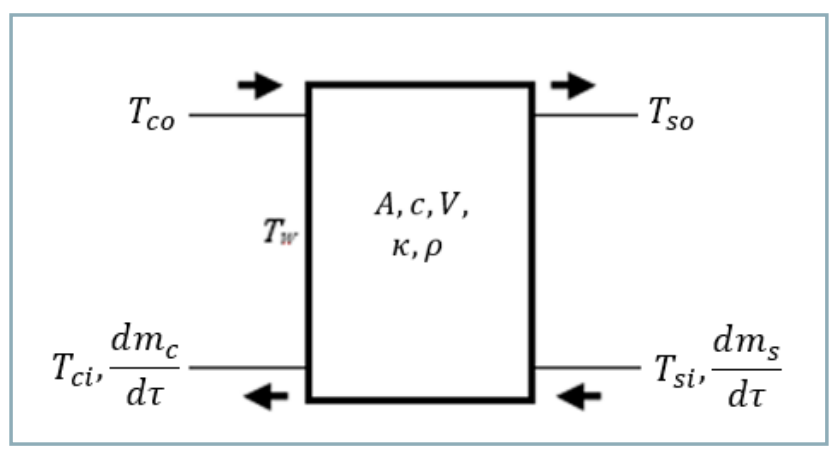

Fig. 3 Scheme of the storage 
The construction yields that $T_{s o} \equiv T_{c i}$ this temperature will be denoted as $T_{s}$. The mathematical model is as follows:

$$
\begin{aligned}
c_{s} \cdot V_{s} \cdot \rho_{s} \cdot \frac{d T_{s}}{d \tau}= & c_{c} \frac{d m_{c}}{d \tau}\left(T_{s}(\tau)-T_{w}(\tau)\right)-c_{s} \frac{d m_{s}}{d \tau}\left(T_{s}(\tau)-T_{s i}(\tau)\right) \\
& -\kappa_{s} \cdot A_{s}\left(T_{s}(\tau)-T_{w}(\tau)\right)
\end{aligned}
$$

where:

$c_{s} \quad-$ specific heat of the working fluid in the storage $\left(\mathrm{J} \cdot \mathrm{kg}^{-1} \cdot \mathrm{K}^{-1}\right)$

$v_{s} \quad-$ volume of the storage $\left(\mathrm{m}^{-3}\right)$

$\rho_{s} \quad-$ density of the working fluid in the storage $\left(\mathrm{kg} \cdot \mathrm{m}^{-3}\right)$

$T_{s} \quad$ - storage temperature $\left({ }^{\circ} \mathrm{C}\right)$

$T_{w} \quad-$ ambient temperature $\left({ }^{\circ} \mathrm{C}\right)$

$\tau \quad-$ time (s)

$c_{c} \quad-$ specific heat of the working fluid in the collector $\left(\mathrm{J} \cdot \mathrm{kg}^{-1} \cdot \mathrm{K}^{-1}\right)$

$m_{c} \quad$ - mass of the working fluid in the collector $(\mathrm{kg})$

$m_{s} \quad$ - mass of the working fluid in the storage $(\mathrm{kg})$

$T_{s i} \quad$ - storage inlet temperature $\left({ }^{\circ} \mathrm{C}\right)$

$\kappa_{s} \quad-$ overall heat transfer coefficient of the storage $\left(\mathrm{W} \cdot \mathrm{m}^{-2} \cdot \mathrm{K}^{-1}\right)$

$A_{s} \quad$ - surface of the storage $\left(\mathrm{m}^{2}\right)$

\section{Heat storage with heat exchanger}

In this type of heat storage, the fluid of collector-loop passes through the fluid of the storage in a heat exchanger pipe. There is no physical contact between the two fluids, but there is less useful surface for the heat transfer in contrast to the mixed heat storage.

This type of heat storage is a more complex device; this is also reflected in the mathematical model. The model was applied to a storage shown in Fig. 4.

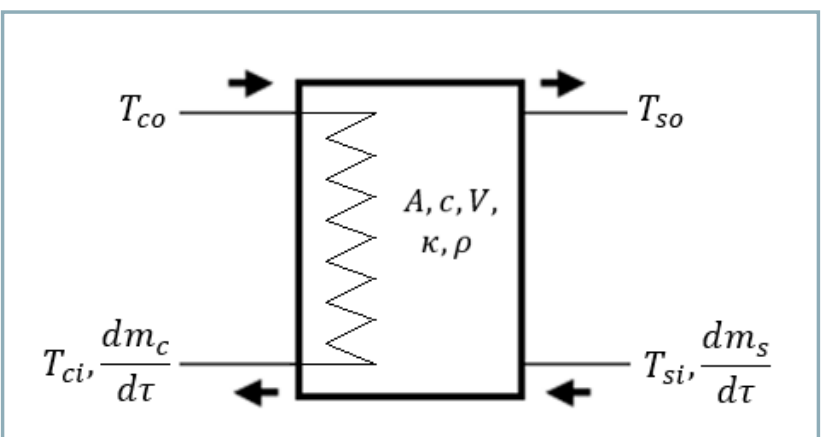

Fig. 4 Scheme of the storage

The mathematical model of the heat storage (Farkas, 1999) is as follows:

$$
\begin{gathered}
T_{c i}(\tau)=\left(T_{c o}(\tau)-T_{s o}(\tau)\right) \cdot \exp \left(\frac{-\kappa_{s} \cdot A_{s}}{c_{s} \cdot \frac{d m_{s}}{d \tau}}\right)+T_{s o}(\tau) \\
C_{s} \cdot V_{s} \cdot \rho_{s} \cdot \frac{d T_{s o}}{d \tau}=c_{s} \frac{d m_{s}}{d \tau}\left(T_{s i}(\tau)-T_{s o}(\tau)\right)+c_{c} \frac{d m_{c}}{d \tau}\left(T_{c o}(\tau)-T_{c i}(\tau)\right)
\end{gathered}
$$

where:

$\tau \quad-$ time (s)

$T_{c i} \quad$ - collector inlet temperature $\left({ }^{\circ} \mathrm{C}\right)$

$T_{c o} \quad$ - collector outlet temperature $\left({ }^{\circ} \mathrm{C}\right)$

$T_{\text {so }} \quad$ - storage outlet temperature $\left({ }^{\circ} \mathrm{C}\right)$

$\kappa_{s} \quad$ - overall heat transfer coefficient of the storage $\left(\mathrm{W} \cdot \mathrm{m}^{-2} \cdot \mathrm{K}^{-1}\right)$

$A_{s} \quad$ - surface of the storage $\left(\mathrm{m}^{2}\right)$

$c_{s} \quad-$ specific heat of the working fluid in the storage $\left(\mathrm{J} \cdot \mathrm{kg}^{-1} \cdot \mathrm{K}^{-1}\right)$

$m_{s} \quad$ - mass of the working fluid in the storage $(\mathrm{kg})$

$V_{s} \quad$ - volume of the storage $\left(\mathrm{m}^{-3}\right)$

$\rho_{s} \quad$ - density of the working fluid int the storage $\left(\mathrm{kg} \cdot \mathrm{m}^{-3}\right)$

$T_{s i} \quad$ - storage inlet temperature $\left({ }^{\circ} \mathrm{C}\right)$

$c_{c} \quad-$ specific heat of the working fluid in the collector $\left(\mathrm{J} \cdot \mathrm{kg}^{-1} \cdot \mathrm{K}^{-1}\right)$

$m_{c} \quad-$ mass of the working fluid in the collector $(\mathrm{kg})$

\section{Metrics of comparison}

For the comparison of the validation of the models, the following metrics were used.

The error $(\varepsilon)$ between the measured/studied $(T)$ and the calculated/compared $\left(T^{\prime}\right)$ temperature is defined as follows:

$$
\varepsilon(\tau)=\int_{\tau_{0}}^{\tau}\left(T(t)-T^{\prime}(t)\right)^{2} d t
$$

which is similar to the least-squares method. This metric is capable of rating the $T$ function on the basis of every point of its domain.

The maximal difference $(\Delta)$ indicating the maximal deviation is:

$$
\Delta=\max \left(\left|\left(T(\tau)-T^{\prime}(\tau)\right)\right|\right)
$$

This metric rates the $T$ function on the basis of one point of its domain.

\section{Results and discussion}

Simulation results are discussed in this section, showing the setups of the simulations, resulting figures and the numerical values of the used metrics.

\section{Comparison of the collector models}

Simulation setup consists of the two collector models and the measured data. The models have been provided with the same input data and the output temperatures of the models have been compared to the measured outlet temperature. The block-oriented representation of this system can be seen in Fig. 5.

Technical parameters of the H-V collector were:

- collector width: $0.5 \mathrm{~m}$;

- collector length: $1 \mathrm{~m}$;

- specific heat of the working fluid (water): $4,200 \mathrm{~J} \cdot \mathrm{kg}^{-1} \cdot \mathrm{K}^{-1}$. 


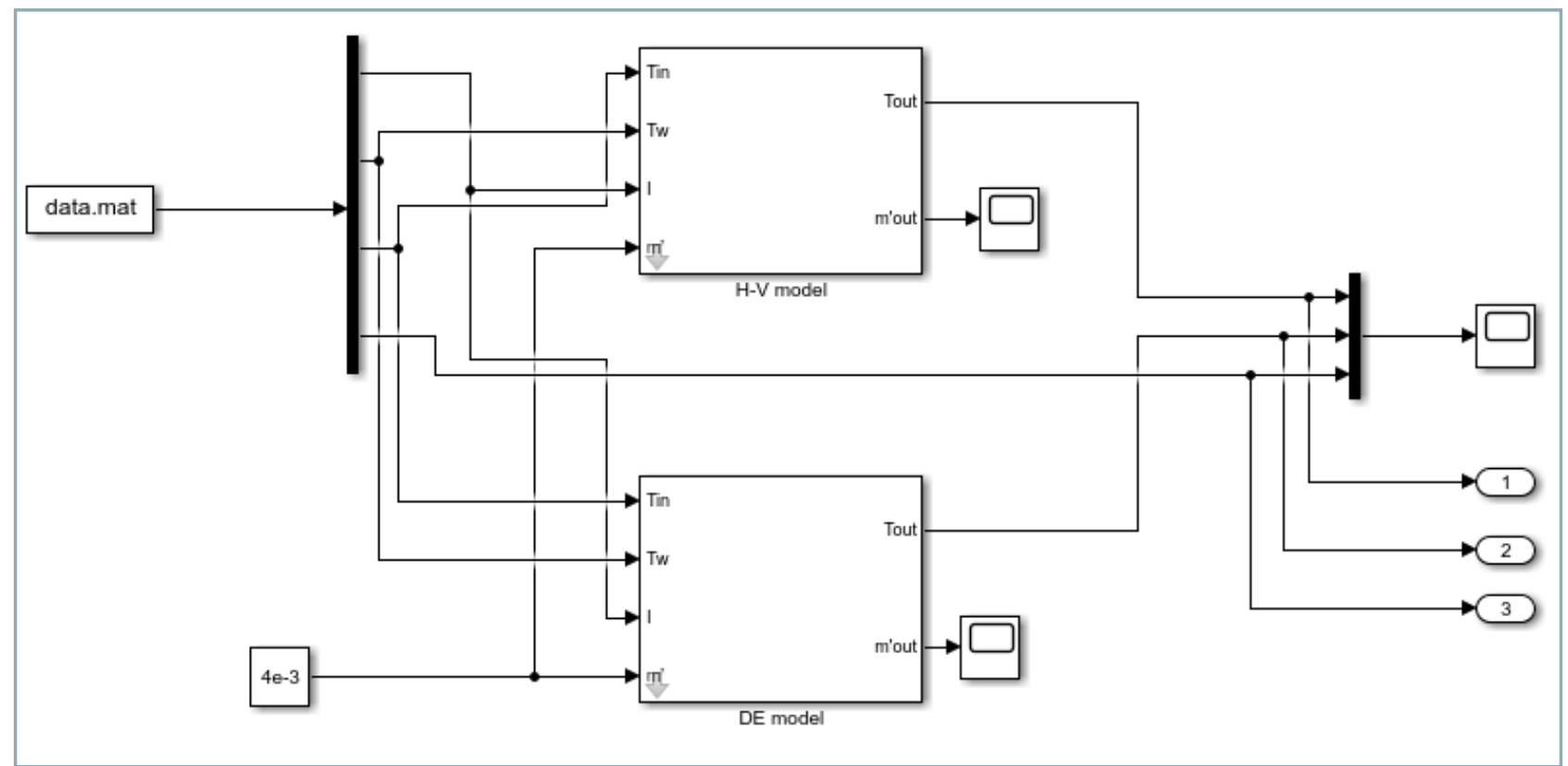

Fig. 5 Block-oriented model for collector comparison

The $\kappa_{a w}$ and $\kappa_{m w}$ parameters had to be identified for the collector by means of a measured data set:

- heat transfer coefficient between the absorber and environment: $38.9 \mathrm{~W} \cdot \mathrm{m}^{-2} \cdot \mathrm{K}^{-1}$;

- heat transfer coefficient between the working fluid and environment: $37.6 \mathrm{~W} \cdot \mathrm{m}^{-2} \cdot \mathrm{K}^{-1}$.

Technical parameters of the DE collector were:

- collector width: $0.5 \mathrm{~m}$;

- collector length: $1 \mathrm{~m}$;

- collector volume: $0.0037 \mathrm{~m}^{3}$;

- specific heat of the working fluid (water): $4,200 \mathrm{~J} \cdot \mathrm{kg}^{-1} \cdot \mathrm{K}^{-1}$;

- density of the working fluid (water): $1,000 \mathrm{~kg} \cdot \mathrm{m}^{-3}$;

- initial temperature: $20^{\circ} \mathrm{C}$.

The $\eta_{o}$ and $\kappa$ parameters had to be identified for the collector by means of the same data used for the $\mathrm{H}-\mathrm{V}$ model. Their numerical values are:

- heat transfer coefficient: $33.6 \mathrm{~W} \cdot \mathrm{m}^{-2} \cdot \mathrm{K}^{-1}$;

- optical efficiency: 0.89 .

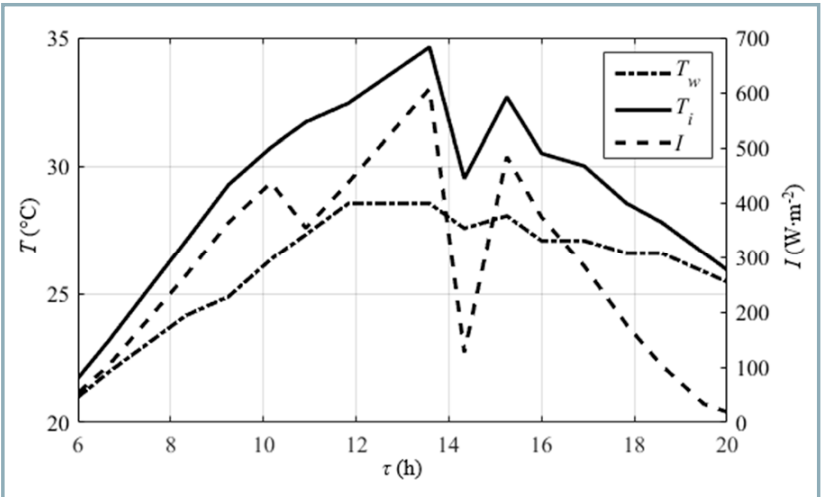

Fig. 6 Inlet, ambient temperature and global radiation
In the present stage of the work, the simulation was carried out by means of measured data including global radiation, inlet and ambient temperature, as shown in Fig. 6.

Collector pump had a constant mass flow of $0.004 \mathrm{~kg} \cdot \mathrm{s}^{-1}$.

Start time of the simulation was $6 \mathrm{AM}$ and the duration of the simulation was $14 \mathrm{~h}$.

Fig. 7 shows the resulting outlet temperatures observed during simulations and Table 1 shows the metrics of the comparison. The $\mathrm{H}-\mathrm{V}$ model is less accurate than the $\mathrm{DE}$ model, but it takes lower amount of parameters into account. The similarity of simulation results was anticipated, since the solution of the DE model has a form similar to the $\mathrm{H}-\mathrm{V}$ model. The accuracy difference between the two models is in the acceptable rate for further studies. The H-V model is more capable of running on an embedded system, such as a Raspberry Pi, due to its simplicity.

Table 1 Results of the comparison

\begin{tabular}{|c|c|c|}
\hline & H-V model & DE model \\
\hline \hline$\varepsilon(\tau=72000)$ & $39,846.63$ & $28,818.62$ \\
\hline$\Delta$ & 2.5246 & 1.9957 \\
\hline
\end{tabular}

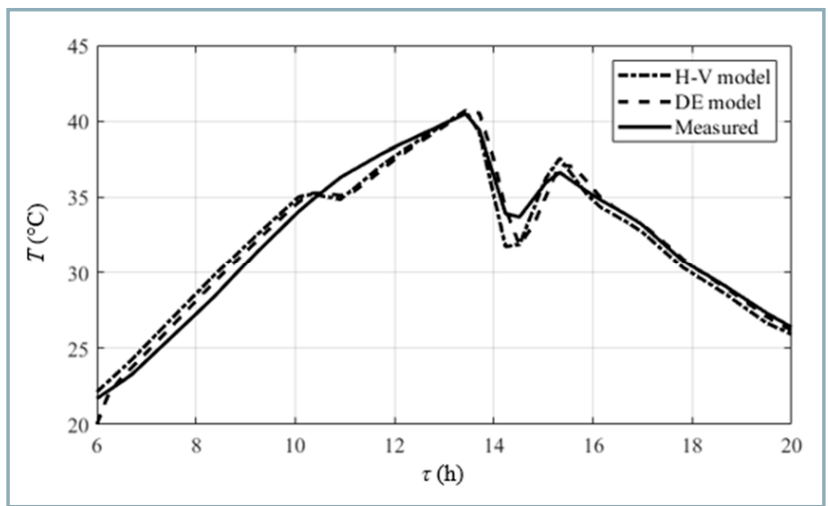

Fig. 7 Outlet temperature of the collectors 


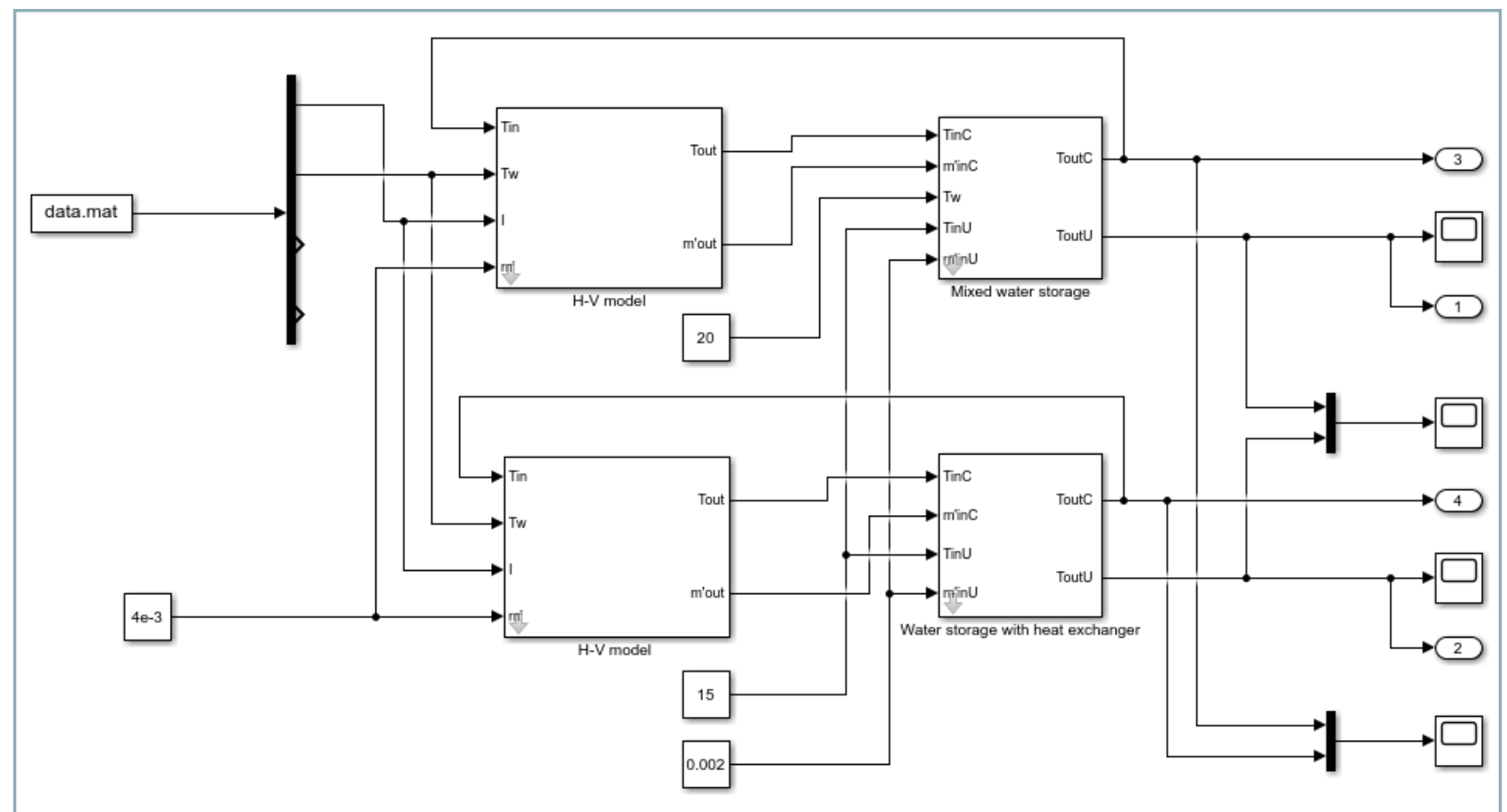

Fig. 8 Block-oriented model for heat storage comparison using $\mathrm{H}-\mathrm{V}$ model

Table 2 Results of the simulations

\begin{tabular}{|c|c|c|c|c|}
\hline & H-Vci & H-Vso & DEci & DEso \\
\hline \hline$\varepsilon(\tau=72000)$ & 531989.81 & 531989.81 & 524906.58 & 524906.58 \\
\hline$\Delta$ & 4.86 & 4.86 & 4.89 & 4.89 \\
\hline
\end{tabular}

\section{Simulation of the storage models}

Goal of this simulation is to study the previously compared collector models in a system. Each collector model was attached to the two storage models and the outlet temperatures of the storages were compared. The blockoriented model of the simulation with the H-V model is shown in Fig. 8. Considering the DE model, simulation setup was identical with exception of the collector model.

Simulation input data were the same as in the comparison of the collector models (Fig. 6).

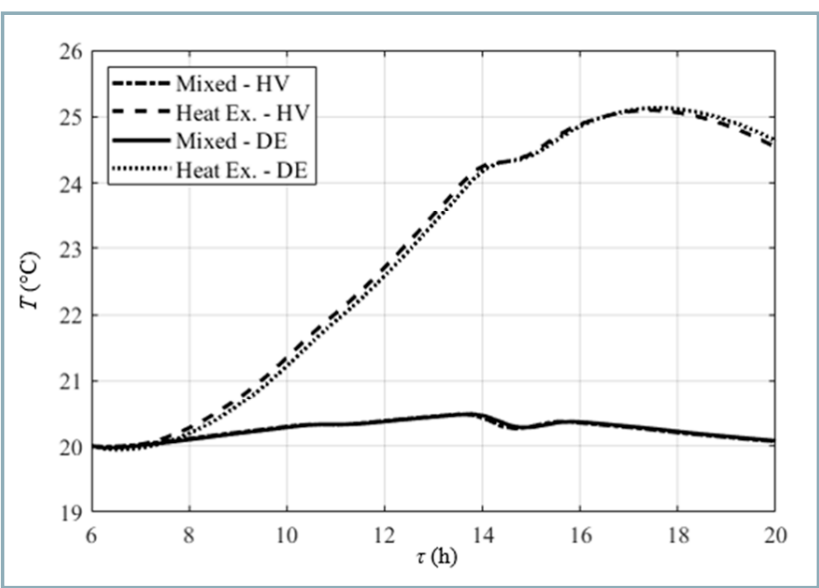

Fig. 9 Collector inlet temperatures of the storages
Technical parameters of both storages were:

- storage surface: $0.375 \mathrm{~m}^{2}$;

- storage volume: $0.15 \mathrm{~m}^{3}$;

- specific heat of the working fluid (water): $4,200 \mathrm{~J} \cdot \mathrm{kg}^{-1} \cdot \mathrm{K}^{-1}$;

- density of the working fluid (water): $1,000 \mathrm{~kg} \cdot \mathrm{m}^{-3}$;

- heat transfer coefficient: $1,200 \mathrm{~W} \cdot \mathrm{m}^{-2} \cdot \mathrm{K}^{-1}$.

The storage models are white-box models, so there was no need for identification.

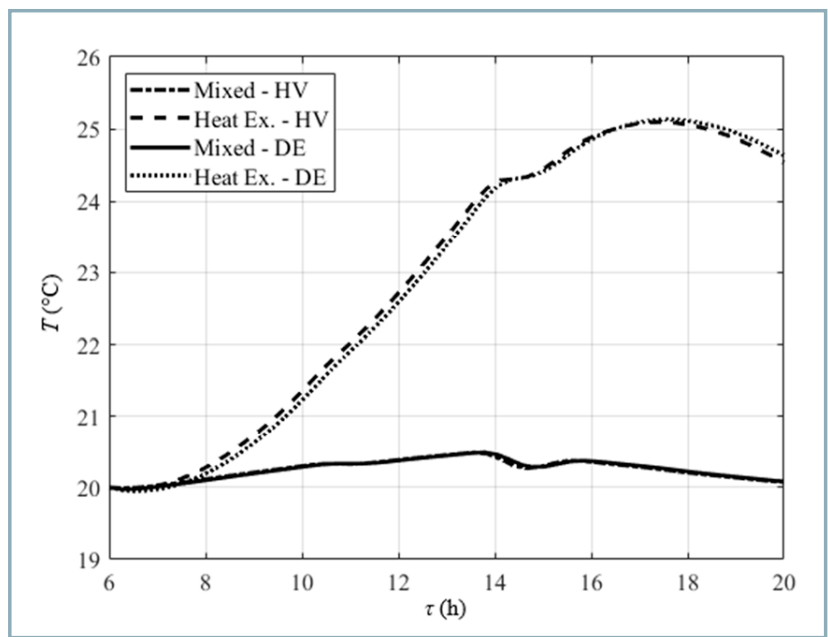

Fig. 10 Storage outlet temperatures of the storages 
Collector pump had a constant mass flow of $0.004 \mathrm{~kg} \cdot \mathrm{s}^{-1}$ and the pump of the storages had a constant mass flow of $0.002 \mathrm{~kg} \cdot \mathrm{s}^{-1}$.

The ambient temperature was set to $20^{\circ} \mathrm{C}$, the user input temperature was $15^{\circ} \mathrm{C}$ and the initial storage temperature was $20^{\circ} \mathrm{C}$.

The time of the start of the simulation was $6 \mathrm{AM}$, the duration of the simulation was $14 \mathrm{~h}$.

Fig. 9 and Fig. 10 show the resulting temperatures observed during the simulation and Table 2 shows the numerical values of the used metrics. The difference in results is basically a slight shift in time, which is in the acceptable range. This simulation shows that the difference in the output between the $\mathrm{H}-\mathrm{V}$ and the DE models is nearly vanishing if they are used in a system, indicating that the $\mathrm{H}-\mathrm{V}$ model is feasible for carrying out further studies, the HIL simulation in a physical system.

\section{Conclusion}

This paper compares two mathematical models of a solar thermal collector - the H-V model and the DE model. The DE model takes into account higher amount of parameters than the H-V model, yet it is more complex. Model parameters were identified on the basis of measurements. Simulation was performed on the basis of the developed SimSolar block-oriented software. Comparison results showed that the greatest difference in accuracy of the models was $2.52{ }^{\circ} \mathrm{C}$, which is in the acceptable range for carrying out the simulations using either of the collector models. Furthermore, solar collector models were tested in a system using different models of heat storages. This test showed that the accuracy difference was even lower, almost negligible $\left(0.03{ }^{\circ} \mathrm{C}\right)$ if heat exchangers were used in the system.

On the basis of the results, it can be concluded that the $\mathrm{H}-\mathrm{V}$ model is more suitable for usage in a hardware-in-theloop simulation for its simplicity. This type of simulation can be achieved using an embedded system, such as Raspberry Pi. Further development can be achieved by the HIL simulation using physical devices.

\section{Acknowledgements}

This work was supported by the Mechanical Engineering Doctoral School, Szent István University, Gödöllő, Hungary.

\section{References}

BILČÍK, M. - BOŽIKOVÁ, M. - PETROVIĆ, A. - MALÍNEK, M. CVIKLOVIČ, V. - OLEJÁR, M. - ARDONOVÁ, V. 2018. Analysis of selected photovoltaic panels operating parameters as a function of partial shading and intensity of reflected radiation. In Acta Technologica Agriculturae, vol. 21, no. 1, pp. 14-17.

DUFFIE, J. A. - BECKMAN, W. A. 2013. Solar Engineering of Thermal Processes. New York: John Wiley \& Sons, Inc., pp. 386-387. ISBN 978-0-470-87366-3.

FARKAS, I. 1999. Computer Simulation. Gödöllő: University of Agriculture, p. 45.

ILYAS, A. - AYYUB, M. - KHAN, M. R. - JAIN, A. - HUSAIN, M. 2018. Realisation of incremental conductance the MPPT algorithm for a solar photovoltaic system. In International Journal of Ambient Energy, vol. 39, no. 8, pp. 873-884.

KYN, M. - URBAN, M. 2013. TRNSYS software model of solar system with long-term storage. In Advanced Materials Research, vol. 649, pp. 303-306.

LACOSTE, B. - WOLF, A. - WITZIG, A. - MARKLIN, A. 2010. Polysun: $\mathrm{PV}$, wind and power-heat cogeneration in one design tool. In Proceedings of the $5^{\text {th }}$ European PV-Hybrid and Mini-Grid Conference, 2010, April 29-30, Tarragona, Spain, Ostbayerisches Technologie-Transfer-Institut e.V., pp. 1-8. ISBN 978-3-941785-15-1. PATERNO, F. 2000. Model-based design and evaluation of interactive applications. London: Springer-Verlag London. ISBN 978-1-85233-155-9.

TÓTH, J. - FARKAS, I. 2017. Developing a Simulink library for solar energy applications. In R\&D in Mechanical Engineering Letters, vol. 16, pp. 89-95.

TRNSYS Manual. 2009. vol 1. http://web.mit.edu/parmstr/Public/ Documentation/01-GettingStarted.pdf

VELASQUEZ, D. R. - COLLAZOS, V. T. - MINES, J. M. 2017. A lowcost hardware-in-the-loop real time simulation of control systems. In Proceedings of the 2017 IEEE 24 ${ }^{\text {th }}$ International Congress on Electronics, Electrical Engineering and Computing, INTERCON 2017, 2017, August 15-18, Cusco, Peru, Curran Associates, Inc. ISBN 978-150906362-8. 